\title{
Interplay between epigallocatechin-3-gallate and ionic strength during amyloid aggregation
}

\author{
Mantas Ziaunys ${ }^{\text {Corresp., }}{ }^{1}$, Kamile Mikalauskaite ${ }^{1}$, Andrius Sakalauskas ${ }^{1}$, Vytautas Smirnovas ${ }^{1}$ \\ 1 Institute of Biotechnology, Life Sciences Center, Vilnius University, Vilnius, Lithuania \\ Corresponding Author: Mantas Ziaunys \\ Email address: mantas.ziaunys@gmc.vu.It
}

The formation and accumulation of protein amyloid aggregates is linked with multiple amyloidoses, including neurodegenerative Alzheimer's or Parkinson's disease. The mechanism of such fibril formation is impacted by various environmental conditions, which greatly complicates the search for potential anti-amyloid compounds. One of these factors is solution ionic strength, which varies between different aggregation protocols during in vitro drug screenings. In this work, we examine the interplay between ionic strength and a well-known protein aggregation inhibitor - epigallocatechin-3-gallate. We show that changes in solution ionic strength have a major impact on the compound's inhibitory effect, reflected in both aggregation times and final fibril structure. We also observe that this effect is unique to different amyloid-forming proteins, such as insulin, alpha-synuclein and amyloid-beta. 


\section{Interplay between epigallocatechin-3-gallate and ionic 2 strength during amyloid aggregation}

3 Mantas Ziaunys*, Kamile Mikalauskaite, Andrius Sakalauskas, Vytautas Smirnovas

4 Institute of Biotechnology, Life Sciences Center, Vilnius University, Vilnius, Lithuania

5 *Corresponding Author:

6 Mantas Ziaunys

7 Sauletekio al. 7, Vilnius, LT-10257, Lithuania

8 Email address: mantas.ziaunys@gmc.vu.lt

9 Abstract

The formation and accumulation of protein amyloid aggregates is linked with multiple amyloidoses, including neurodegenerative Alzheimer's or Parkinson's disease. The mechanism of such fibril formation is impacted by various environmental conditions, which greatly complicates the search for potential anti-amyloid compounds. One of these factors is solution ionic strength, which varies between different aggregation protocols during in vitro drug screenings. In this work, we examine the interplay between ionic strength and a well-known protein aggregation inhibitor - epigallocatechin-3-gallate. We show that changes in solution ionic strength have a major impact on the compound's inhibitory effect, reflected in both aggregation times and final fibril structure. We also observe that this effect is unique to different amyloidforming proteins, such as insulin, alpha-synuclein and amyloid-beta.

\section{Introduction}

Protein aggregation into amyloid fibrils is associated with the onset and progression of many amyloidoses (Baker \& Rice, 2012), including widespread neurodegenerative disorders, such as Alzheimer's or Parkinson's disease (Knowles, Vendruscolo \& Dobson, 2014; Chiti \& Dobson, 2017). Countless studies and years of research have resulted in very few disease-modifying drugs (Maurer et al., 2018; Park et al., 2020), with most potential aggregation-inhibiting compounds failing at various stages of clinical trials (Mehta et al., 2017; Cummings et al., 2020), which, in turn, has not allowed to slow down the ever-increasing occurrence of amyloid-related disorders and even more cases are projected for the upcoming decades (Hebert et al., 2013; Arthur et al., 2016). This makes it vitally important to obtain a better understanding of protein aggregation (Cohen et al., 2012), as well as their interaction (Fusco et al., 2018) with drug molecules. Currently, there are more than a hundred compounds which have shown potential in having either a direct or indirect effect on the appearance and accumulation of these disease-related protein/peptide aggregates (Williams, Sorribas \& Howes, 2011). It was also shown that there are 
multiple modes of interaction between potential drug molecules and fibrils, which include binding along their surface, inside cavities or by interacting with specific amino acids (Landau et al., 2011).

One of the main problems during anti-amyloid compound screenings is the impact of environmental conditions on both the aggregation rate and mechanism, as well as protein interaction. Multiple factors, such as protein concentration (Sakalauskas, Ziaunys \& Smirnovas, 2019), temperature (Tanaka et al., 2006; Colby et al., 2009), agitation (Petkova et al., 2005), ionic strength (Bousset et al., 2013), pH (Sneideris et al., 2015) or denaturant concentration (Colby et al., 2009) can influence the initial amyloidogenic protein state (Nettleton et al., 2000), the course and rate of aggregation (Morel et al., 2010; Noormägi et al., 2015) and the resulting fibril conformation/morphology (Morel et al., 2010; Zidar \& Merzel, 2011; Nicoud et al., 2015). Taking into consideration that amyloid-inhibitor interactions may be highly-selective (Wang, Dong \& Sun, 2012; Zhuang et al., 2016; Liu et al., 2018; Fusco et al., 2018), distinct fibrillization intermediates or fibrils can have specific affinity to the drug molecules in question. This effect was demonstrated during alpha-synuclein and epigallocatechin-3-gallate (EGCG) experiments, where it was observed that changes to the solution's $\mathrm{pH}$ value or sample agitation drastically improve or impair the molecule's effectiveness at inhibiting alpha-synuclein aggregation (Sneideris et al., 2019; Sternke-Hoffmann et al., 2020).

One of these factors, which requires a more in-depth analysis, is ionic strength. It has been demonstrated that the solution's ionic strength (usually modulated by the addition of $\mathrm{NaCl}$ (Jain \& Udgaonkar, 2010)) can influence the rate of aggregation by altering electrostatic interactions between protein molecules (Ziaunys, Sneideris \& Smirnovas, 2018). It was also shown that this factor can determine the conformation and morphology of fibrils that form during aggregation (Bousset et al., 2013; Gaspar et al., 2020). In addition, ionic strength can influence compound interactions with fibrils and even cause conformation changes to preformed aggregates (Mikalauskaite et al., 2020). Taking all of this into account, it appears that ionic strength plays an important role in multiple stages of the amyloid formation process and could significantly alter experimental results and their conclusions regarding anti-amyloid compounds. Since there are many groups screening for potential aggregation-inhibiting drugs (Findeis, 2000; Huang, Chao \& $\mathrm{Hu}, 2020$ ) and each one has their own preferred/optimized fibrillization protocols (Giorgetti et al., 2018), there is a substantial number of different ionic strength conditions used. Considering the aforementioned effects that this factor may have on amyloid formation, as well as the possible highly-selective nature of anti-amyloid compounds, it is possible that certain potent drugs may appear ineffective under specific ionic strength conditions, leading to false-negative results.

In order to examine the magnitude of the effect that ionic strength has on anti-amyloid drug screening, one of the most well-known and commonly used compounds was chosenepigallocatechin-3-gallate (EGCG). It has been shown on numerous studies, both in vitro and in silico (Ngo et al., 2017; Tavanti, Pedone \& Menziani, 2020), that EGCG can alter the aggregation pathway of amyloidogenic proteins, leading to either off-pathway structures or slowing down the rate of fibril formation (Andrich \& Bieschke, 2015). It is also known that this 
polyphenolic molecule undergoes autoxidation at neutral $\mathrm{pH}$, which increases its anti-amyloid potency and minimizes further structural changes during the aggregation reaction (An, Feng \& Zeng, 2017; Sneideris et al., 2019).

In this work, the inhibitory effect of preoxidized EGCG was determined under a range of ionic strength conditions (below and above the typical physiological ionic strength (Kawai, Wray \& Güth, 1990)), using two neurodegenerative-disease-related proteins/peptides - amyloid-beta (Alzheimer's disease) and alpha-synuclein (Parkinson's disease), as well as insulin, which is associated with localized injection site amyloidosis (Knowles, Vendruscolo \& Dobson, 2014), but is widely used as a model protein in amyloid studies. Due to the distinct amino acid sequences and aggregation conditions of the selected proteins/peptides, it was possible to gain a deeper insight into the effect that this factor has on EGCG inhibitory potential. We show how the interplay between ionic strength and EGCG has a unique effect on each protein/peptide aggregation kinetics and resulting fibril structures.

\section{Materials and Methods}

\section{Epigallocatechin gallate preparation}

Epigallocatechin-3-gallate (Fluorochem, cat. No. M01719) was dissolved in a $100 \mathrm{mM}$ potassium phosphate ( $\mathrm{pH}$ 7.4) buffer to a final concentration of $10 \mathrm{mM}$. Due to EGCG undergoing autoxidation at neutral $\mathrm{pH}$ under two of the three tested aggregation conditions, which changes the efficiency of its inhibition (Sneideris et al., 2019; Wei et al., 2016), the compound was preoxidized before being used in aggregation experiments by distributing the solution into $1.5 \mathrm{~mL}$ test-tubes ( $1 \mathrm{~mL}$ final volume) and incubating at $60^{\circ} \mathrm{C}$ for 72 hours without agitation (Ziaunys et al., 2021). The solution's absorbance spectra were scanned every 24 hours using a Shimadzu UV-1800 spectrophotometer in the range from $240 \mathrm{~nm}$ to $600 \mathrm{~nm}(1 \mathrm{~nm}$ steps, $3 \mathrm{~mm}$ pathlength cuvette) and baseline corrected. Prior to measurements, an aliquot of the solution was diluted 100 times by its initial reaction buffer. No significant changes to the absorbance spectra were observed after the 72 hour mark, indicating that this time frame is sufficient for a complete oxidation process (Supplementary Figure S1). The final solution was then filtered through a $0.22 \mu \mathrm{m}$ syringe filter and stored at $4^{\circ} \mathrm{C}$. Only the oxidized form of EGCG was used in all further experiments.

\section{Aggregation reactions}

Human recombinant insulin powder (Sigma-Aldrich, cat. No. 91077C) was dissolved in $20 \%$ acetic acid ( $\mathrm{pH} \sim 1.8$, (Foderà, Van De Weert \& Vestergaard, 2010)) solutions, containing a range of $\mathrm{NaCl}$ concentrations (from $100 \mathrm{mM}$ to $800 \mathrm{mM}$ ) to a final protein concentration of 400 $\mu \mathrm{M}\left(\varepsilon_{280}=6335 \mathrm{M}^{-1} \mathrm{~cm}^{-1}\right)$. The insulin stock solutions were then combined with $10 \mathrm{mM}$ ThT (Sigma-Aldrich cat. No. T3516) and $10 \mathrm{mM}$ EGCG stock solutions and diluted using their respective $20 \%$ acetic acid solutions to a final protein concentration of $200 \mu \mathrm{M}, 100 \mu \mathrm{M}$ ThT and $25 \mu \mathrm{M}$ EGCG. Control samples contained an equal volume of $100 \mathrm{mM}$ potassium phosphate (pH 7.4) buffer solution in place of EGCG. The reaction solutions were then distributed into 96well non-binding plates (cat. No 3881, Fisher Scientific, final volume $100 \mu \mathrm{L}$, six repeats for 
114

115

116

117

118

119

120

121

122

123

124

125

126

127

128

129

130

131

132

133

134

135

136

137

138

139

140

141

142

143

144

145

146

147

148

149

150

151

152

153

each condition), which were sealed using Nunc sealing-tape. Aggregation kinetics were monitored at $60^{\circ} \mathrm{C}$ without agitation, using a ClarioStar Plus plate reader (440 $\mathrm{nm}$ excitation and $480 \mathrm{~nm}$ emission wavelengths) with measurements taken every 5 minutes. Samples were placed in the 96-well plate in an alternating style (Supplementary Figure S2) to avoid any possible nonhomogenous temperature variations throughout the plate having an effect on the average aggregation kinetics.

Alpha-synuclein was purified as described previously (Šneideris et al., 2015), lyophilized and stored at $-20^{\circ} \mathrm{C}$. Prior to aggregation experiments, alpha-synuclein powder was dissolved in 20 $\mathrm{mM}$ potassium phosphate ( $\mathrm{pH}$ 7.4) buffers containing a range of $\mathrm{NaCl}$ concentrations (from 100 $\mathrm{mM}$ to $800 \mathrm{mM}$ ) and filtered through a $0.22 \mu \mathrm{m}$ syringe filter, after which the protein solution was diluted to $250 \mu \mathrm{M}\left(\varepsilon_{280}=5960 \mathrm{M}^{-1} \mathrm{~cm}^{-1}\right)$. The alpha-synuclein stock solutions were then combined with $10 \mathrm{mM}$ ThT and $10 \mathrm{mM}$ EGCG stock solutions and diluted using their respective buffer solutions to a final protein concentration of $100 \mu \mathrm{M}, 100 \mu \mathrm{M}$ ThT and $100 \mu \mathrm{M}$ EGCG. The reaction solutions were distributed to 96-well plates as described previously (final volume $80 \mu \mathrm{L}$, each well contained a $3 \mathrm{~mm}$ glass bead). Aggregation kinetics were monitored at $37^{\circ} \mathrm{C}$ with constant 600 RPM orbital agitation.

Amyloid beta (1-42) was purified as described in Supplementary Material, stored on ice ( $~ 5$ minutes) until its concentration was determined by integrating the chromatographic UV absorbance peak $\left(\varepsilon_{280}=1490 \mathrm{M}^{-1} \mathrm{~cm}^{-1}\right)$, after which it was immediately diluted with a $20 \mathrm{mM}$ sodium phosphate $(\mathrm{pH}$ 6.3) buffer solution in a 1:2 ratio to yield a $\mathrm{pH} 7.0$ peptide solution. Afterwards, it was further diluted using a $20 \mathrm{mM}$ sodium phopshate $(\mathrm{pH} 7.0)$ buffer to reach a peptide concentration of $5 \mu \mathrm{M}$. The peptide solution was then combined with $20 \mathrm{mM}$ sodium phosphate ( $\mathrm{pH} 7.0$ ) buffers, containing either 0 or $1.6 \mathrm{M} \mathrm{NaCl}, 10 \mathrm{mM}$ ThT and $10 \mathrm{mM}$ EGCG stock solutions to a final peptide concentration of $2 \mu \mathrm{M}, 20 \mu \mathrm{M}$ ThT, $25 \mu \mathrm{M}$ EGCG and a range of $\mathrm{NaCl}$ concentrations (from $0 \mathrm{mM}$ to $700 \mathrm{mM}$ ). All buffer, ThT and EGCG solutions were kept at $4^{\circ} \mathrm{C}$ prior to use. The reaction solutions were then distributed to a 96-well plate as described previously (final volume $80 \mu \mathrm{L}$ ). Aggregation kinetics were monitored at $25^{\circ} \mathrm{C}$ without agitation.

For all three proteins/peptides, the EGCG concentrations were initially optimized to result in a 3 to 4 -fold increase in the relative $t_{50}$ values. The half-time $\left(t_{50}\right)$, lag time $\left(t_{\text {lag }}\right)$ and aggregation rate values were determined by fitting each curve with a Boltzmann sigmoidal equation as described previously (Ziaunys et al., 2021).

\section{Fourier-transform infrared (FTIR) spectroscopy}

Each condition samples were collected from their respective 96-well plates and combined to a final volume of $\sim 0.6 \mathrm{~mL}$ (insulin fibrils) or $\sim 0.48 \mathrm{~mL}$ (alpha-synuclein). The combined samples were centrifuged at $12500 \mathrm{RPM}$ for $20 \mathrm{~min}$, after which the supernatant was removed. The fibril pellets were resuspended into $0.5 \mathrm{~mL} \mathrm{D}_{2} \mathrm{O}$ with $400 \mathrm{mM} \mathrm{NaCl}$ (exchanging the solution to $\mathrm{D}_{2} \mathrm{O}$ removes the $\mathrm{H}_{2} \mathrm{O}$-specific absorbance in the Amide I region, while the addition of $\mathrm{NaCl}$ improves aggregate sedimentation (Mikalauskaite et al., 2020)). This centrifugation and resuspension procedure was repeated 4 times. After the final centrifugation, the fibril pellets were resuspended into $0.1 \mathrm{~mL} \mathrm{D}_{2} \mathrm{O}$ without $\mathrm{NaCl}$. Each sample was sonicated for $5 \mathrm{~s}$ using a 
154 Bandelin Sonopuls Ultrasonic homogenizer, equipped with a MS-72 sonication tip (20\% of

155

156

157

158

159

160

161

162

163

164

165

166

167

168

169

170

171

172

173

174

175

176

177

178

179

180

181

182

183

184

185

186

187

188

189

190

191

192

193 maximum power, constant sonication). FTIR spectra were acquired as described previously (Sneideris et al., 2019) using a Bruker Invenio S FTIR spectrometer. A $\mathrm{D}_{2} \mathrm{O}$ spectrum was subtracted from each sample's spectrum, which were then normalized between $1595-1700 \mathrm{~cm}^{-}$ 1. All data processing was done using GRAMS software. In the case of amyloid beta, the resulting spectra did not meet the quality necessary for an accurate analysis due to the significantly lower concentration of fibrils and the resulting low signal-to-noise ratio.

\section{ThT and EGCG absorbance assay}

Insulin fibrils were prepared by incubating the previously described insulin aggregation reaction solutions in $2.0 \mathrm{~mL}$ non-binding test-tubes ( $2 \mathrm{~mL}$ final volume) at $60^{\circ} \mathrm{C}$ without agitation for 24 hours. The fibril samples were then centrifuged at $12500 \mathrm{RPM}$ for $20 \mathrm{~min}$ and resuspended into $2 \mathrm{~mL}$ of $20 \%$ acetic acid solutions, containing either $100 \mathrm{mM}$ or $800 \mathrm{mM} \mathrm{NaCl}$. This centrifugation and resuspension procedure was repeated 4 times. After this, both fibril samples were sonicated for $10 \mathrm{~min}$ on ice, using a MS-73 sonication tip (40\% of maximum power, $30 \mathrm{~s}$ sonication/ $30 \mathrm{~s}$ rest intervals). The resulting sonicated fibril solutions were combined with 10 $\mathrm{mM}$ ThT and $10 \mathrm{mM}$ EGCG stock solutions, resulting in a 2-fold diluted fibril sample, containing $0 \mu \mathrm{M}, 50 \mu \mathrm{M}$ or $100 \mu \mathrm{M}$ ThT and $0 \mu \mathrm{M}, 50 \mu \mathrm{M}$ or $100 \mu \mathrm{M}$ EGCG. For control samples, the fibril solution was replaced with a $20 \%$ acetic acid solution, containing either 100 $\mathrm{mM}$ or $800 \mathrm{mM} \mathrm{NaCl}$.

All samples were then vigorously agitated and mixed for $10 \mathrm{~s}$, incubated at room temperature without agitation for $20 \mathrm{~min}$ and centrifuged at 12500 RPM for $20 \mathrm{~min}$. From each sample, a portion of the supernatant was carefully removed. The supernatant was then scanned using a Shimadzu UV-1800 spectrophotometer in the wavelength range from $240 \mathrm{~nm}$ to $600 \mathrm{~nm}$ in a 10 $\mathrm{mm}$ pathlength cuvette. For each condition, three spectra were scanned, averaged and baseline corrected based on the absorbance value at $600 \mathrm{~nm}$.

\section{Results}

The inhibitory potential of oxidized epigallocatechin-3-gallate (further referred to as EGCG) was first examined on insulin, under a range of ionic strength conditions. At $0 \mathrm{mM} \mathrm{NaCl}$, insulin aggregation in the presence of EGCG did not complete in a reasonable timeframe (the aggregation extended into time frames where sample evaporation and dye stability became an issue). When the concentration of $\mathrm{NaCl}$ was low $(100 \mathrm{mM})$, the aggregation half-time $\left(\mathrm{t}_{50}\right)$ had an average value of $\sim 1700$ minutes in the presence of EGCG, while the control sample's $\mathrm{t}_{50}$ was $\sim 370$ minutes (Figure 1A). In this case, the relative $t_{50}$ value was $\sim 4$, indicating a strong aggregation-inhibiting effect (Figure 1B). When the concentration of $\mathrm{NaCl}$ was increased to 200 $\mathrm{mM}$, the relative $t_{50}$ value remained similar, however, both the control and EGCG samples aggregated significantly quicker. Further increase in ionic strength led to a considerable shift in the relative $t_{50}$ values (from $\sim 4$ to $\sim 1.5-2$ ), while the half-times of samples continued to decrease with rising $\mathrm{NaCl}$ concentrations. A one-way ANOVA Bonferroni means comparison analysis displayed a significant difference between the $100-200 \mathrm{mM}$ and $300-800 \mathrm{mM}$ group relative $\mathrm{t}_{50}$ values $(\mathrm{p}=0.01)$ with no significant variation within each group. The decreasing $\mathrm{t}_{50}$ values also 
194

195

196

197

198

199

200

201

202

203

204

205

206

207

208

209

210

211

212

213

214

215

216

217

218

219

220

221

222

223

224

225

226

227

228

229

230

231

232

233

234

greatly reduced the stochasticity of spontaneous aggregation (Supplementary Figure S3), which was quite large at lower ionic strength conditions (likely due to a significantly longer lag time, coupled with the spontaneous nature of unseeded aggregation (Foderà et al., 2008)). The lag time $\left(t_{\text {lag }}\right)$ of all reactions followed a similar tendency as the $t_{50}$ values and the aggregation rate did not experience significant differences under all conditions (Supplementary Figure S6). Plotting a lag time dependence on the square root of $\mathrm{NaCl}$ concentration (Zhou \& Pang, 2018; Perez-Jimenez et al., 2004) (Supplementary Figure S6) revealed that there was a discontinuity at $300 \mathrm{mM} \mathrm{NaCl}$, after which the increasing ionic strength had a significantly lesser effect on the lag time.

The end-point fluorescence intensity values of fibril-bound ThT were not used as a means of identifying the inhibitory potential of EGCG for any of the three proteins/peptides used in this study. This was due to the fact that exogenous compounds may cause ThT fluorescence intensity variations by direct interaction, inner filter or non-conjugated FRET effects (Hudson et al., 2009; Ran et al., 2011; Ziaunys, Sakalauskas \& Smirnovas, 2020). Differences in fibril secondary structure or morphology may also alter its signal intensity (Ziaunys, Sakalauskas \& Smirnovas, 2020; Bousset et al., 2013).

The resulting fibril secondary structures were analysed using FTIR spectroscopy in order to determine whether EGCG and changes in ionic strength had any influence on insulin aggregate conformations. When the reaction solutions did not contain EGCG, insulin fibrils appear to have undergone a structural transition between low and high $\mathrm{NaCl}$ concentration conditions. At low ionic strength $(100-200 \mathrm{mM} \mathrm{NaCl})$, the FTIR spectra (Figure 1C) main maxima are at $1626 \mathrm{~cm}^{-}$ 1 , which is associated with the presence of beta-sheet hydrogen bonds (Barth, 2007). The second derivative spectra (Figure 1E) also contain minima at $1642 \mathrm{~cm}^{-1}$ (weaker beta-sheet hydrogen bonds), $1659 \mathrm{~cm}^{-1}$ and $1672 \mathrm{~cm}^{-1}$ (turn/loop motifs), as well as $1729 \mathrm{~cm}^{-1}$ (deuterated carboxyl groups (Surmacz-Chwedoruk et al., 2012)). When ionic strength is higher, the main maximum shifts to $1628-1629 \mathrm{~cm}^{-1}$, indicating weaker beta-sheet hydrogen bonding than in the lower ionic strength samples. The band associated with deuterated carboxyl groups $\left(1729 \mathrm{~cm}^{-1}\right)$ is also reduced at higher $\mathrm{NaCl}$ concentrations.

When the reaction solutions contained $25 \mu \mathrm{M}$ EGCG, the main FTIR spectrum (Figure 1D) maximum position is at $1627-1628 \mathrm{~cm}^{-1}$ under all ionic strength conditions. Unlike insulin fibrils without EGCG, the spectra of fibrils, prepared at different $\mathrm{NaCl}$ concentrations, are very similar and only a slight decreasing of $1642 \mathrm{~cm}^{-1}$ band can be observed in second derivative spectra with increased ionic strength. (Figure 1F). This means that the presence of the inhibitor is also a factor in determining the conformation of the aggregate and it stabilises a certain secondary structure.

When alpha-synuclein was aggregated under a range of ionic strength conditions with and without EGCG, we observed a similar reduction in $\mathrm{t}_{50}$ values with increasing $\mathrm{NaCl}$ concentration (Figure 2A), as was the case for insulin aggregation. However, the change in relative $\mathrm{t}_{50}$ was quite different (Figure 2B). When the solution's ionic strength was increased from $100 \mathrm{mM}$ to $200 \mathrm{mM} \mathrm{NaCl}$, the relative $\mathrm{t}_{50}$ value increased, indicating a stronger inhibitory effect of EGCG. After this point, the value gradually decreased with rising $\mathrm{NaCl}$ concentrations, eventually becoming within margin of error to the control. A Bonferroni means comparison revealed that

Peer) reviewing PDF | (2021:07:63972:1:0:NEW 17 Sep 2021) 
235 the relative $t_{50}$ values above $400 \mathrm{mM} \mathrm{NaCl}$ were significantly different $(p=0.01)$ from the 200 $236 \mathrm{mM} \mathrm{NaCl}$ condition values. Unlike with insulin aggregation, there was no sudden shift in the

237

238

239

240

241

242

243

244

245

246

247

248

249

250

251

252

253

254

255

256

257

258

259

260

261

262

263

264

265

266

267

268

269

270

271

272

273

274

275

276 relative $t_{50}$ values, however, the higher stochasticity at low ionic strength conditions was quite similar (Supplementary Figure S4). As with insulin at $0 \mathrm{mM} \mathrm{NaCl}$ conditions, alpha-synuclein did not aggregate in a reasonable timeframe when in the presence of EGCG (the aggregation began to occur only after 2000 min for samples without EGCG, which created the issue of sample evaporation and ThT instability (Foderà et al., 2008)). The aggregation rate values were mostly within margin of error without any major deviations, while $t_{\text {lag }}$ values followed a similar tendency as $t_{50}$ values (Supplementary Figure S6). Unlike with insulin, a discontinuity in the lag time dependence on the square root of $\mathrm{NaCl}$ concentration only appeared at $500 \mathrm{mM} \mathrm{NaCl}$ (Supplementary figure S6).

The FTIR spectra of alpha-synuclein fibrils prepared in the absence (Figure 2C, E) or presence (Figure 2D, F) of EGCG show a gradual conformational shift with increasing $\mathrm{NaCl}$ concentration, reflected by the appearance of a minimum in the second derivative spectra at 1615 $\mathrm{cm}^{-1}$, which is related to stronger hydrogen bonds in the beta-sheet structure. While the main maxima (and the main minima in the second derivative spectra) all share the same position (1624 $\mathrm{cm}^{-1}$, related to hydrogen bonds in the beta-sheet structure), the minimum at $1642 \mathrm{~cm}^{-1}$ (weak hydrogen bonds) disappears at the highest ionic strength conditions when there is no EGCG present in solution. When alpha-synuclein aggregates with the inhibitor, this minimum is almost undetectable at low ionic strength conditions $(100 \mathrm{mM} \mathrm{NaCl})$, then becomes visible $(200-300$ $\mathrm{mM} \mathrm{NaCl}$ ) and then shifts towards $1637 \mathrm{~cm}^{-1}$. EGCG also appears to cause minor variations in the region associated with turn/loop motifs $\left(1660-1680 \mathrm{~cm}^{-1}\right)$ upon an increasing concentration of $\mathrm{NaCl}$. Overall, the structural changes seem to be a lot less sudden than was the case with insulin fibrils, which falls in line with the gradual change to relative $\mathrm{t}_{50}$ values.

In the case of amyloid beta (1-42), it was possible to track the impact of ionic strength on its aggregation and the effect of EGCG from $0 \mathrm{mM} \mathrm{NaCl}$ due to the relatively quick aggregation reaction times (Supplementary Figure S5). The first notable thing is that the $t_{50}$ values experienced a higher change when in the absence of EGCG, where they shifted from $~ 50$ minutes at $0 \mathrm{mM} \mathrm{NaCl}$ to 20-30 minutes at higher $\mathrm{NaCl}$ concentrations (Figure $3 \mathrm{~A}$ ). The $\mathrm{t}_{50}$ values in the presence of EGCG only appeared to experience minimal variations. The relative $t_{50}$ values (Figure 3B) did not follow any significant trend, as all values were mostly within margin of error. However, a Bonferroni means comparison analysis revealed that the $0 \mathrm{mM} \mathrm{NaCl}$ relative $t_{50}$ values were significantly different $(p=0.01)$ from the $300-600 \mathrm{mM} \mathrm{NaCl}$ condition values. Unlike with both other proteins, the inhibitory effect of EGCG did not undergo considerable changes, as even $700 \mathrm{mM} \mathrm{NaCl}$ conditions resulted in $\sim 2.5$ times higher $\mathrm{t}_{50}$ values when compared to the control. The $t_{\text {lag }}$ and aggregation rate values also did not display any significant variations, however, the lag time dependence on the square root of $\mathrm{NaCl}$ concentration was distinct from both the insulin and alpha-synuclein cases. There was a positive trend up to $300 \mathrm{mM} \mathrm{NaCl}$, followed by a linear decrease at increasing ionic strength conditions. This indicates that the charge screening effect of $\mathrm{NaCl}$ (up to $300 \mathrm{mM}$ ) had a positive effect on the lag time values (Supplementary Figure S6). In the case of amyloid beta, it was not possible to obtain high quality FTIR spectra due to the low peptide concentration $(2 \mu \mathrm{M})$. Using a higher 
277

278

279

280

281

282

283

284

285

286

287

288

289

290

291

292

293

294

295

296

297

298

299

300

301

302

303

304

305

306

307

308

309

310

311

312

313

314

315

316

317

amount of each sample in the described FTIR method or exchanging the fibrils into $\mathrm{D}_{2} \mathrm{O}$ with 10 $\mathrm{kDa}$ concentrators also did not yield sufficient quality results. Such a low concentration and the presence of a relatively high amount of EGCG also prohibited the use of other fibril characterization methods, such as CD spectroscopy or dye-binding assays.

Since it is known that the solution's ionic strength may influence fibril and amyloidophilic molecule interactions, the observed results could be caused by several ionic-strength-related factors, such as EGCG-fibril affinity and interaction or competitive binding with ThT. In order to examine if different $\mathrm{NaCl}$ concentrations have an effect ThT and EGCG interactions, the dye molecule absorbance spectra were scanned when they are separately (after which the spectra were combined) and together, as described in the Materials and Method section. When the combined spectra of ThT and EGCG are compared to the spectra of ThT-EGCG mixtures under $100 \mathrm{mM}$ and $800 \mathrm{mM} \mathrm{NaCl}$ conditions, there do not appear to be any major differences (Supplementary Figure S7A, B). A change in their interaction would likely be seen as a shift in spectra maximum positions or lower/higher absorbance at their characteristic bands, however, this is not the case.

To test the competitive binding hypothesis, both ThT and EGCG were mixed with insulin fibrils under $100 \mathrm{mM}$ and $800 \mathrm{mM} \mathrm{NaCl}$ conditions (separately and together), after which the fibril samples were centrifuged and their supernatant absorbance spectra were scanned. In the case of $50 \mu \mathrm{M}$ ThT and $50 \mu \mathrm{M}$ EGCG, we observed a lower absorbance value at $412 \mathrm{~nm}$ (characteristic maximum ThT absorbance peak) and an increase in absorbance at $300 \mathrm{~nm}$ (position where both EGCG and ThT absorb light) when comparing low and high ionic strength conditions (Supplementary Figure S7C, D). A similar effect was seen when $100 \mu \mathrm{M}$ ThT and $100 \mu \mathrm{M}$ EGCG were used (Supplementary Figure S7E, F). This indicates that higher ionic strength leads to more bound ThT molecules (which is known to be the case for insulin and alpha-synuclein (Mikalauskaite et al., 2020)) and also results in less bound EGCG. These differences, however, are not significant enough to constitute this process as the sole reason for the loss of EGCG inhibitory potential at higher $\mathrm{NaCl}$ concentrations.

\section{Discussion}

Taking all of these results into consideration, it is quite clear that ionic strength plays a major role in both amyloid aggregation, as well as determining the inhibitory potential of EGCG. However, the interplay between ionic strength, EGCG and amyloid proteins appears to be a lot more complex than one would initially assume. The first interesting aspect is that a different concentration of EGCG was required for each protein/peptide to achieve a 3 to 4-fold increase in relative $\mathrm{t}_{50}$ values. For insulin $(\mathrm{pI} \sim 5.3$, condition $\mathrm{pH}=2.4)$ the protein/EGCG ratio was $8: 1$, while for alpha-synuclein $(\mathrm{pI} \sim 4.7$, condition $\mathrm{pH}=7.4)$ it was $1: 1$. Despite an eight times different ratio, the highest increase in $t_{50}$ values was 4 -fold (with similar $t_{50}$ values), indicating that either protein charge or the type of aggregation intermediates may play an important role in the inhibition process. Conversely, amyloid-beta $(\mathrm{pI} \sim 5.8$, condition $\mathrm{pH}=7.0)$ required a $0.08: 1$ ratio to even come close to similar inhibition. This may be due to the relatively fast aggregation of amyloid-beta when compared to both other proteins, thus significantly reducing the possibility of EGCG inhibiting the process. 
318 The second factor is the effect that $\mathrm{NaCl}$ concentration has on fibril secondary structure. It is a

319

320

321

322

323

324

325

326

327

328

329

330

331

332

333

334

335

336

337

338

339

340

341

342

343

344

345

346

347

348

349

350

351

352

353

354

355

356

357

358

known fact that the solution's ionic strength can lead to the formation of distinct fibril conformations (Bousset et al., 2013; Gaspar et al., 2020) and the potential inhibitor molecule may have a weaker or stronger effect, based on its interaction with the aggregate. In this case, we observe both gradual (alpha-synuclein) and quick (insulin) fibril structural variations with increasing ionic strength. The second factor is that EGCG, by itself, induces such structural variations, as seen in the case of insulin fibrils at $100 \mathrm{mM} \mathrm{NaCl}$. Since both $\mathrm{NaCl}$ and EGCG can influence aggregate conformations, these factors are likely at play simultaneously, which increases the overall complexity of the fibrillization process.

Another interesting aspect is that there seems to be an optimal ionic strength, which showcases the best inhibitory potential of EGCG. Based on relative half-time values, low ionic strength conditions favour the strongest inhibition for insulin and alpha-synuclein, while for amyloid-beta (1-42) it appears to be almost identical at all $\mathrm{NaCl}$ concentrations above $0 \mathrm{mM}$. Conversely, certain conditions reduce the potency of EGCG to such a point, that it may almost appear as ineffective. Examining the charge screening of $\mathrm{NaCl}$ for each protein, it seems that alphasynuclein is less susceptible to the screening effect when compared to insulin, while for amyloidbeta, an initial increase in ionic strength slightly improved the peptide-EGCG interaction (Supplementary Figure S6). Taking into account that this is just one out of a whole plethora of potential anti-aggregation compounds, it is very likely that other compound effectiveness also depends on the solution's ionic strength. This leads to the possibility of certain drug molecules being classified as not having any effect on amyloid aggregation if the reaction conditions are not suitable for them specifically. A similar observation was also made with EGCG and environmental conditions, where the compound was only potent at certain solution $\mathrm{pH}$ values (Sternke-Hoffmann et al., 2020).

We also have to discuss the possible role that ionic strength has in determining EGCG effectiveness. The first possibility is that the increasing $\mathrm{NaCl}$ concentration makes it difficult for EGCG to interact with either the native state protein or the various aggregation intermediates through electrostatic effects. This does not appear to be an issue when it interacts with fibrils, as both $100 \mathrm{mM}$ and $800 \mathrm{mM} \mathrm{NaCl}$ led to a similar number of bound EGCG molecules. The second possibility is that EGCG is only effective against certain types of aggregation intermediate species, as such interaction with intermediates has been shown previously (Andrich \& Bieschke, 2015). If ionic strength changes what type of nuclei or protofibril species form, inhibition may not occur for the different type of aggregate. This does not explain, however, why EGCG seems to also change the conformation of aggregates, unless it does so by preventing certain nuclei from forming. The third probable cause is related to the aggregation kinetics. In general, amyloid fibril formation proceeds slower at low ionic strength conditions, as seen for all three proteins/peptides used in this study. If new nuclei appear less frequently, then the same concentration of EGCG would have a higher chance of preventing their formation and subsequent elongation into fibrils. It is also possible that multiple factors are at play simultaneously, resulting in a highly complex environment-based inhibitor-protein interaction.

\section{Conclusions}

Peer] reviewing PDF | (2021:07:63972:1:0:NEW 17 Sep 2021) 
359

360

361

362

363

364

365

366

367

368

369

370

371

372

373

374

375

376

377

378

379

380

381

382

383

384

385

386

387

388

389

390

391

392

393

394

395

396

These results show that each amyloidogenic protein/peptide may have specific ionic strength conditions where they are most susceptible to the inhibitory effect of EGCG. It appears that the inhibitor is generally most potent at lower ionic strength conditions for insulin and alphasynuclein and an increasing concentration of $\mathrm{NaCl}$ reduces its effectiveness. This is not the case for amyloid-beta (1-42), where inhibition is quite similar under all ionic strength conditions above $100 \mathrm{mM} \mathrm{NaCl}$. In addition, the interplay between ionic strength and the inhibitor molecule is highly complex, which affects multiple aggregation parameters, such as aggregation kinetics and fibril conformations. Considering that this is just one of the multiple possible variables in protein aggregation studies, it showcases the importance of taking into account every environmental factor during amyloid formation.

\section{Funding}

This research was funded by the grant no. S-SEN-20-3 from the Research Council of Lithuania.

\section{References}

An T-T, Feng S, Zeng C-M. 2017. Oxidized epigallocatechin gallate inhibited lysozyme fibrillation more strongly than the native form. Redox biology 11:315-321. DOI: 10.1016/j.redox.2016.12.016.

Andrich K, Bieschke J. 2015. The effect of (-)-epigallo-catechin-(3)-gallate on amyloidogenic proteins suggests a common mechanism. DOI: 10.1007/978-3-319-18365-7_7.

Arthur KC, Calvo A, Price TR, Geiger JT, Chiò A, Traynor BJ. 2016. Projected increase in amyotrophic lateral sclerosis from 2015 to 2040. Nature Communications 7:12408. DOI: $10.1038 /$ ncomms 12408 .

Baker KR, Rice L. 2012. The Amyloidoses: Clinical Features, Diagnosis And Treatment. Methodist DeBakey Cardiovascular Journal 8:3-7. DOI: 10.14797/mdcj-8-3-3.

Barth A. 2007. Infrared spectroscopy of proteins. Biochimica et Biophysica Acta (BBA) Bioenergetics 1767:1073-1101. DOI: 10.1016/j.bbabio.2007.06.004.

Bousset L, Pieri L, Ruiz-Arlandis G, Gath J, Jensen PH, Habenstein B, Madiona K, Olieric V, Böckmann A, Meier BH, Melki R. 2013. Structural and functional characterization of two alpha-synuclein strains. Nature Communications 4:2575. DOI: 10.1038/ncomms3575.

Chiti F, Dobson CM. 2017. Protein Misfolding, Amyloid Formation, and Human Disease: A Summary of Progress Over the Last Decade. Annual Review of Biochemistry 86:27-68. DOI: 10.1146/annurev-biochem- 061516-045115.

Cohen SIA, Vendruscolo M, Dobson CM, Knowles TPJ. 2012. From macroscopic measurements to microscopic mechanisms of protein aggregation. Journal of Molecular Biology 421:160171. DOI: $10.1016 / j . j m b .2012 .02 .031$.

Colby DW, Giles K, Legname G, Wille H, Baskakov I V., DeArmond SJ, Prusiner SB. 2009. Design and construction of diverse mammalian prion strains. Proceedings of the National Academy of Sciences of the United States of America 106:20417-22. DOI: 10.1073/pnas.0910350106. 
397

398

399

400

401

402

403

404

405

406

407

408

409

410

411

412

413

414

415

416

417

418

419

420

421

422

423

424

425

426

427

428

429

430

431

432

433

434

435

Cummings J, Lee G, Ritter A, Sabbagh M, Zhong K. 2020. Alzheimer's disease drug development pipeline: 2020. Alzheimer's \& Dementia: Translational Research \& Clinical Interventions 6:1-29. DOI: 10.1002/trc2.12050.

Findeis MA. 2000. Approaches to discovery and characterization of inhibitors of amyloid $\beta$ peptide polymerization. Biochimica et Biophysica Acta - Molecular Basis of Disease 1502:76-84. DOI: 10.1016/S0925-4439(00)00034-X.

Foderà V, Groenning M, Vetri V, Librizzi F, Spagnolo S, Cornett C, Olsen L, van de Weert M, Leone M. 2008. Thioflavin T Hydroxylation at Basic $\mathrm{pH}$ and Its Effect on Amyloid Fibril Detection. The Journal of Physical Chemistry B 112:15174-15181. DOI: 10.1021/jp805560c.

Foderà V, Librizzi F, Groenning M, Van De Weert M, Leone M. 2008. Secondary nucleation and accessible surface in insulin amyloid fibril formation. Journal of Physical Chemistry B 112:3853-3858. DOI: 10.1021/jp710131u.

Foderà V, Van De Weert M, Vestergaard B. 2010. Large-scale polymorphism and auto-catalytic effect in insulin fibrillogenesis. Soft Matter 6:4413-4419. DOI: 10.1039/c0sm00169d.

Fusco G, Sanz-Hernandez M, Ruggeri FS, Vendruscolo M, Dobson CM, De Simone A. 2018. Molecular determinants of the interaction of EGCG with ordered and disordered proteins. Biopolymers 109:e23117. DOI: 10.1002/bip.23117.

Gaspar R, Lund M, Sparr E, Linse S. 2020. Anomalous Salt Dependence Reveals an Interplay of Attractive and Repulsive Electrostatic Interactions in $\alpha$-synuclein Fibril Formation. $Q R B$ Discovery 1. DOI: 10.1017/qrd.2020.7.

Giorgetti S, Greco C, Tortora P, Aprile F. 2018. Targeting Amyloid Aggregation: An Overview of Strategies and Mechanisms. International Journal of Molecular Sciences 19:2677. DOI: 10.3390/ijms 19092677.

Hebert LE, Weuve J, Scherr PA, Evans DA. 2013. Alzheimer disease in the United States (20102050) estimated using the 2010 census. Neurology 80:1778-1783. DOI: 10.1212/WNL.0b013e31828726f5.

Huang LK, Chao SP, Hu CJ. 2020. Clinical trials of new drugs for Alzheimer disease. Journal of Biomedical Science 27:1-13. DOI: 10.1186/s12929-019-0609-7.

Hudson SA, Ecroyd H, Kee TW, Carver JA. 2009. The thioflavin T fluorescence assay for amyloid fibril detection can be biased by the presence of exogenous compounds. FEBS Journal 276:5960-5972. DOI: 10.1111/j.1742-4658.2009.07307.x.

Jain S, Udgaonkar JB. 2010. Salt-Induced Modulation of the Pathway of Amyloid Fibril Formation by the Mouse Prion Protein. Biochemistry 49:7615-7624. DOI: 10.1021/bi100745j.

Kawai M, Wray JS, Güth K. 1990. Effect of ionic strength on crossbridge kinetics as studied by sinusoidal analysis, ATP hydrolysis rate and x-ray diffraction techniques in chemically skinned rabbit psoas fibres. Journal of Muscle Research and Cell Motility 11:392-402. DOI: $10.1007 / \mathrm{BF} 01739760$. 
436

437

438

439

440

441

442

443

444

445

446

447

448

449

450

451

452

453

454

455

456

457

458

459

460

461

462

463

464

465

466

467

468

469

470

471

472

473

474

475

Knowles TPJ, Vendruscolo M, Dobson CM. 2014. The amyloid state and its association with protein misfolding diseases. Nature Reviews Molecular Cell Biology 15:384-396. DOI: $10.1038 / \mathrm{nrm} 3810$.

Landau M, Sawaya MR, Faull KF, Laganowsky A, Jiang L, Sievers SA, Liu J, Barrio JR, Eisenberg D. 2011. Towards a Pharmacophore for Amyloid. PLoS Biology 9:25-27. DOI: 10.1371/journal.pbio.1001080.

Liu X, Zhou S, Shi D, Bai Q, Liu H, Yao X. 2018. Influence of EGCG on $\alpha$-synuclein $(\alpha S)$ aggregation and identification of their possible binding mode: A computational study using molecular dynamics simulation. Chemical Biology \& Drug Design 91:162-171. DOI: 10.1111/cbdd.13067.

Maurer MS, Schwartz JH, Gundapaneni B, Elliott PM, Merlini G, Waddington-Cruz M, Kristen A V., Grogan M, Witteles R, Damy T, Drachman BM, Shah SJ, Hanna M, Judge DP, Barsdorf AI, Huber P, Patterson TA, Riley S, Schumacher J, Stewart M, Sultan MB, Rapezzi C. 2018. Tafamidis Treatment for Patients with Transthyretin Amyloid Cardiomyopathy. New England Journal of Medicine 379:1007-1016. DOI: 10.1056/NEJMoa1805689.

Mehta D, Jackson R, Paul G, Shi J, Sabbagh M. 2017. Why do trials for Alzheimer's disease drugs keep failing? A discontinued drug perspective for 2010-2015. Expert Opinion on Investigational Drugs 26:735-739. DOI: 10.1080/13543784.2017.1323868.

Mikalauskaite K, Ziaunys M, Sneideris T, Smirnovas V. 2020. Effect of Ionic Strength on Thioflavin-T Affinity to Amyloid Fibrils and Its Fluorescence Intensity. International Journal of Molecular Sciences 21:8916. DOI: 10.3390/ijms21238916.

Morel B, Varela L, Azuaga AI, Conejero-Lara F. 2010. Environmental Conditions Affect the Kinetics of Nucleation of Amyloid Fibrils and Determine Their Morphology. Biophysical Journal 99:3801-3810. DOI: 10.1016/j.bpj.2010.10.039.

Nettleton EJ, Tito P, Sunde M, Bouchard M, Dobson CM, Robinson C V. 2000. Characterization of the Oligomeric States of Insulin in Self-Assembly and Amyloid Fibril Formation by Mass Spectrometry. Biophysical Journal 79:1053-1065. DOI: 10.1016/S00063495(00)76359-4.

Ngo ST, Truong DT, Tam NM, Nguyen MT. 2017. EGCG inhibits the oligomerization of amyloid beta (16-22) hexamer: Theoretical studies. Journal of Molecular Graphics and Modelling 76:1-10. DOI: 10.1016/j.jmgm.2017.06.018.

Nicoud L, Lazzari S, Balderas Barragán D, Morbidelli M. 2015. Fragmentation of Amyloid Fibrils Occurs in Preferential Positions Depending on the Environmental Conditions. The Journal of Physical Chemistry B 119:4644-4652. DOI: 10.1021/acs.jpcb.5b01160.

Noormägi A, Valmsen K, Tõugu V, Palumaa P. 2015. Insulin Fibrillization at Acidic and Physiological $\mathrm{pH}$ Values is Controlled by Different Molecular Mechanisms. The protein journal 34:398-403. DOI: 10.1007/s10930-015-9634-x.

Park J, Egolum U, Parker S, Andrews E, Ombengi D, Ling H. 2020. Tafamidis: A First-in-Class Transthyretin Stabilizer for Transthyretin Amyloid Cardiomyopathy. Annals of 
494

495

496

497

498

499

500

501

502

503

504

505

506

507

508

509

510

511

512

513

514

Pharmacotherapy 54:470-477. DOI: 10.1177/1060028019888489.

Perez-Jimenez R, Godoy-Ruiz R, Ibarra-Molero B, Sanchez-Ruiz JM. 2004. The Efficiency of Different Salts to Screen Charge Interactions in Proteins: A Hofmeister Effect? Biophysical Journal 86:2414-2429. DOI: 10.1016/S0006-3495(04)74298-8.

Petkova AT, Leapman RD, Guo Z, Yau W-M, Mattson MP, Tycko R. 2005. Self-propagating, molecular-level polymorphism in Alzheimer's beta-amyloid fibrils. Science (New York, N.Y.) 307:262-5. DOI: 10.1126/science.1105850.

Ran C, Zhao W, Moir RD, Moore A. 2011. Non-Conjugated Small Molecule FRET for Differentiating Monomers from Higher Molecular Weight Amyloid Beta Species. PLoS ONE 6:e19362. DOI: 10.1371/journal.pone.0019362.

Sakalauskas A, Ziaunys M, Smirnovas V. 2019. Concentration-dependent polymorphism of insulin amyloid fibrils. PeerJ 7:e8208. DOI: 10.7717/peerj.8208.

Šneideris T, Baranauskienè L, Cannon JG, Rutkienė R, Meškys R, Smirnovas V. 2015. Looking for a generic inhibitor of amyloid-like fibril formation among flavone derivatives. PeerJ 3:e1271. DOI: $10.7717 /$ peerj.1271.

Sneideris T, Darguzis D, Botyriute A, Grigaliunas M, Winter R, Smirnovas V. 2015. pH-Driven Polymorphism of Insulin Amyloid-Like Fibrils. PLOS ONE 10:e136602. DOI: 10.1371/journal.pone.0136602.

Sneideris T, Sakalauskas A, Sternke-Hoffmann R, Peduzzo A, Ziaunys M, Buell AK, Smirnovas V. 2019. The Environment Is a Key Factor in Determining the Anti-Amyloid Efficacy of EGCG. Biomolecules 9:1-17. DOI: 10.3390/biom9120855.

Sternke-Hoffmann R, Peduzzo A, Bolakhrif N, Haas R, Buell AK. 2020. The aggregation conditions define whether EGCG is an inhibitor or enhancer of $\alpha$-synuclein amyloid fibril formation. International Journal of Molecular Sciences 21. DOI: 10.3390/ijms21061995.

Surmacz-Chwedoruk W, Nieznańska H, Wójcik S, Dzwolak W. 2012. Cross-seeding of fibrils from two types of insulin induces new amyloid strains. Biochemistry 51:9460-9469. DOI: 10.1021/bi301144d.

Tanaka M, Collins SR, Toyama BH, Weissman JS. 2006. The physical basis of how prion conformations determine strain phenotypes. Nature 442:585-589. DOI: 10.1038/nature04922.

Tavanti F, Pedone A, Menziani MC. 2020. Insights into the effect of curcumin and (-)epigallocatechin-3-gallate on the aggregation of a $\beta(1-40)$ monomers by means of molecular dynamics. International Journal of Molecular Sciences 21:1-15. DOI: 10.3390/ijms21155462.

Wang S-H, Dong X-Y, Sun Y. 2012. Effect of (-)-epigallocatechin-3-gallate on human insulin fibrillation/aggregation kinetics. Biochemical Engineering Journal 63:38-49. DOI: 10.1016/j.bej.2012.02.002.

Wei Y, Chen P, Ling T, Wang Y, Dong R, Zhang C, Zhang L, Han M, Wang D, Wan X, Zhang J. 2016. Certain (-)-epigallocatechin-3-gallate (EGCG) auto-oxidation products (EAOPs) 
515

516

517

518

519

520

521

522

523

524

525

526

527

528

529

530

531

532

533

534

535

536

537

retain the cytotoxic activities of EGCG. Food Chemistry 204:218-226. DOI: 10.1016/j.foodchem.2016.02.134.

Williams P, Sorribas A, Howes MJR. 2011. Natural products as a source of Alzheimer's drug leads. Natural Product Reports 28:48-77. DOI: 10.1039/c0np00027b.

Zhou HX, Pang X. 2018. Electrostatic Interactions in Protein Structure, Folding, Binding, and Condensation. Chemical Reviews 118:1691-1741. DOI: 10.1021/acs.chemrev.7b00305.

Zhuang X, Zhao B, Liu S, Song F, Cui F, Liu Z, Li Y. 2016. Noncovalent Interactions between Superoxide Dismutase and Flavonoids Studied by Native Mass Spectrometry Combined with Molecular Simulations. Analytical Chemistry 88:11720-11726. DOI: 10.1021/acs.analchem.6b03359.

Ziaunys M, Mikalauskaite K, Sakalauskas A, Smirnovas V. 2021. Using lysozyme amyloid fibrils as a means of scavenging aggregation-inhibiting compounds. Biotechnology Journal:2100138. DOI: 10.1002/biot.202100138.

Ziaunys M, Sakalauskas A, Mikalauskaite K, Snieckute R, Smirnovas V. 2021. Temperaturedependent structural variability of prion protein amyloid fibrils. International Journal of Molecular Sciences 22. DOI: 10.3390/ijms22105075.

Ziaunys M, Sakalauskas A, Smirnovas V. 2020. Identifying Insulin Fibril Conformational Differences by Thioflavin-T Binding Characteristics. Biomacromolecules 21:4989-4997. DOI: 10.1021/acs.biomac.0c01178.

Ziaunys M, Sneideris T, Smirnovas V. 2018. Self-inhibition of insulin amyloid-like aggregation. Physical Chemistry Chemical Physics 20:27638-27645. DOI: 10.1039/C8CP04838J.

Zidar J, Merzel F. 2011. Probing amyloid-beta fibril stability by increasing ionic strengths. Journal of Physical Chemistry B 115:2075-2081. DOI: 10.1021/jp109025b. 
Figure 1

Insulin $(200 \mu \mathrm{M})$ aggregation half-time $\left(t_{50}\right)$ values and resulting fibril FTIR spectra.

Insulin aggregation $t_{50}$ values in the absence or presence of $25 \mu \mathrm{M}$ EGCG $(A)$ and relative $t_{50}$ values (B). Relative $t_{50}$ values were obtained by calculating the ratio between average $t_{50}$ of samples with EGCG and average $t_{50}$ without EGCG. FTIR spectra of insulin fibrils prepared under a range of $\mathrm{NaCl}$ concentrations in the absence (C) or presence (D) of $25 \mu \mathrm{M} \mathrm{EGCG}$ and their second derivatives ( $E$ and $F$ respectively). Dotted lines show second derivative positions, which experience variation between different spectra. For each condition, half-time values were calculated from six repeats, error bars are for one standard deviation. All raw kinetic and FTIR data is available as Supplementary Information.
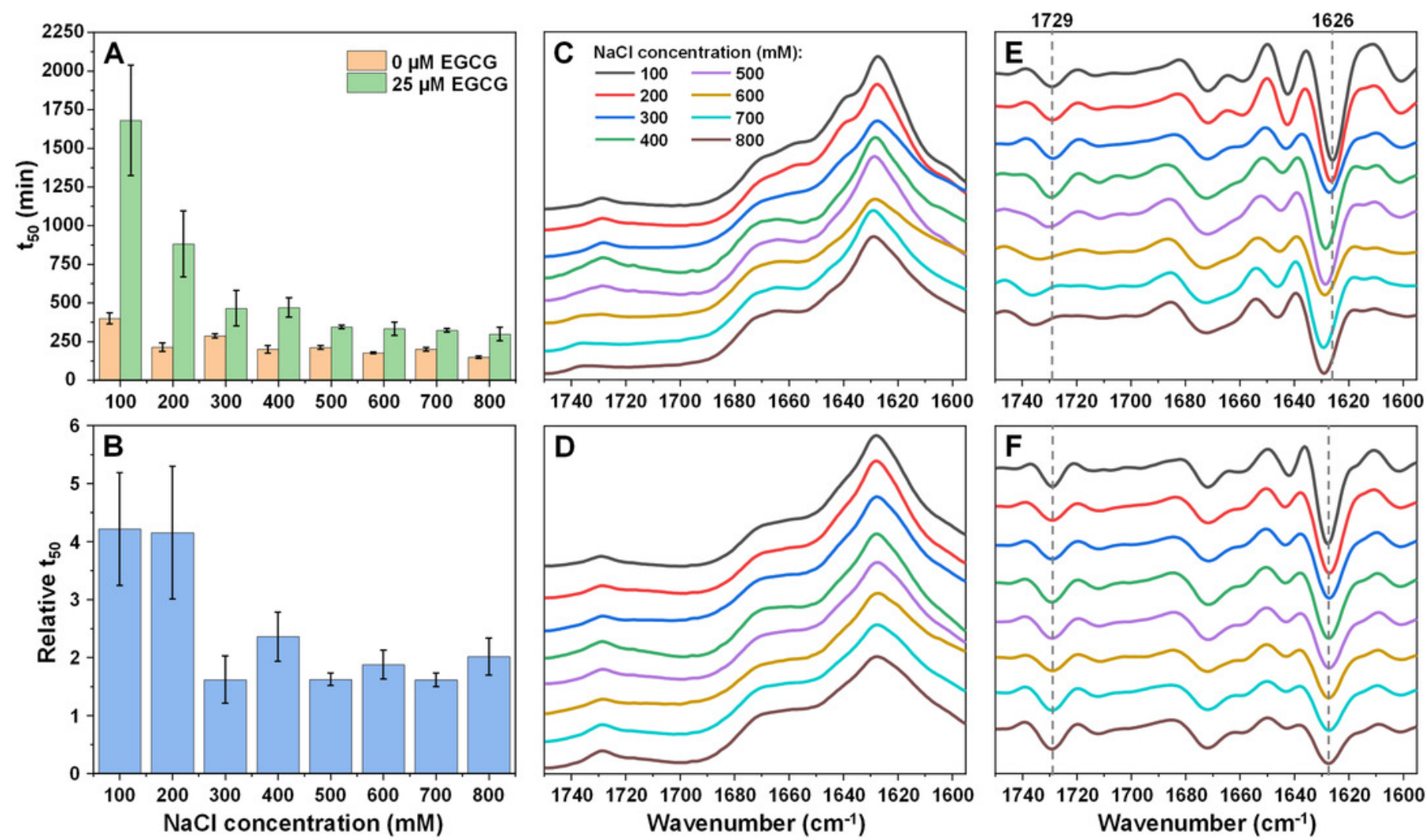
Figure 2

Alpha-synuclein $(100 \mu \mathrm{M})$ aggregation half-time $\left(t_{50}\right)$ values and resulting fibril FTIR spectra.

Alpha-synuclein aggregation $t_{50}$ values in the absence or presence of $100 \mu \mathrm{M}$ EGCG $(\mathrm{A})$ and relative $t_{50}$ values (B). Relative $t_{50}$ values were obtained by calculating the ratio between average $t_{50}$ of samples with EGCG and average $t_{50}$ without EGCG. FTIR spectra of alphasynuclein fibrils prepared under a range of $\mathrm{NaCl}$ concentrations in the absence (C) or presence (D) of $100 \mu \mathrm{M}$ EGCG and their second derivatives ( $E$ and $F$ respectively). Dotted lines show second derivative positions, which experience variation between different spectra. For each condition, half-time values were calculated from six repeats, error bars are for one standard deviation. All raw kinetic and FTIR data is available as Supplementary Information.
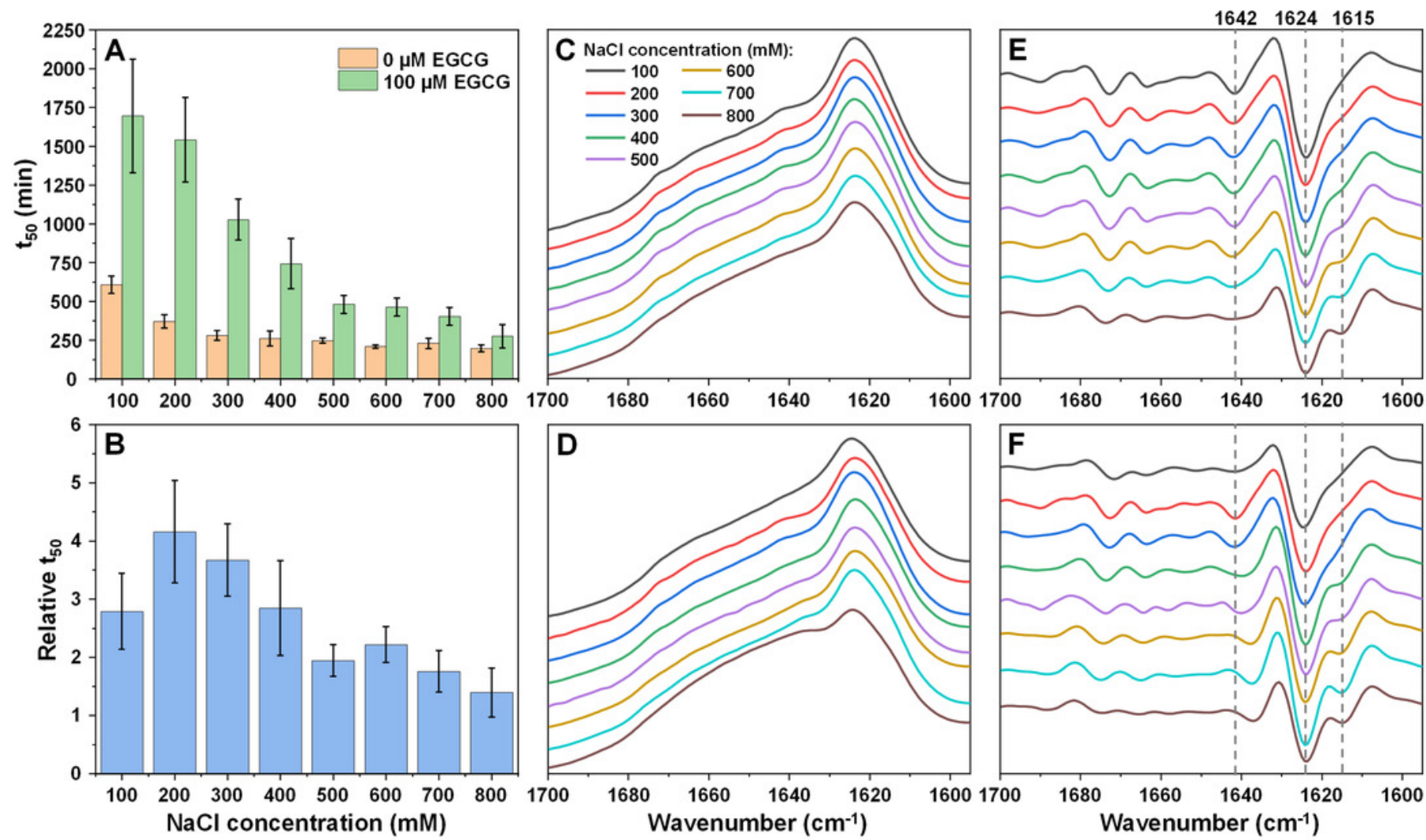
Figure 3

Amyloid-beta (1-42) $(2 \mu \mathrm{M})$ aggregation half-time $\left(t_{50}\right)(A)$ and relative $t_{50}$ values $(B)$ in the absence or presence of $25 \mu \mathrm{M}$ EGCG.

Relative $t_{50}$ values were obtained by calculating the ratio between average $t_{50}$ of samples with EGCG and average $t_{50}$ without EGCG. For each condition, half-time values were calculated from six repeats, error bars are for one standard deviation. All raw kinetic data is available as Supplementary Information.
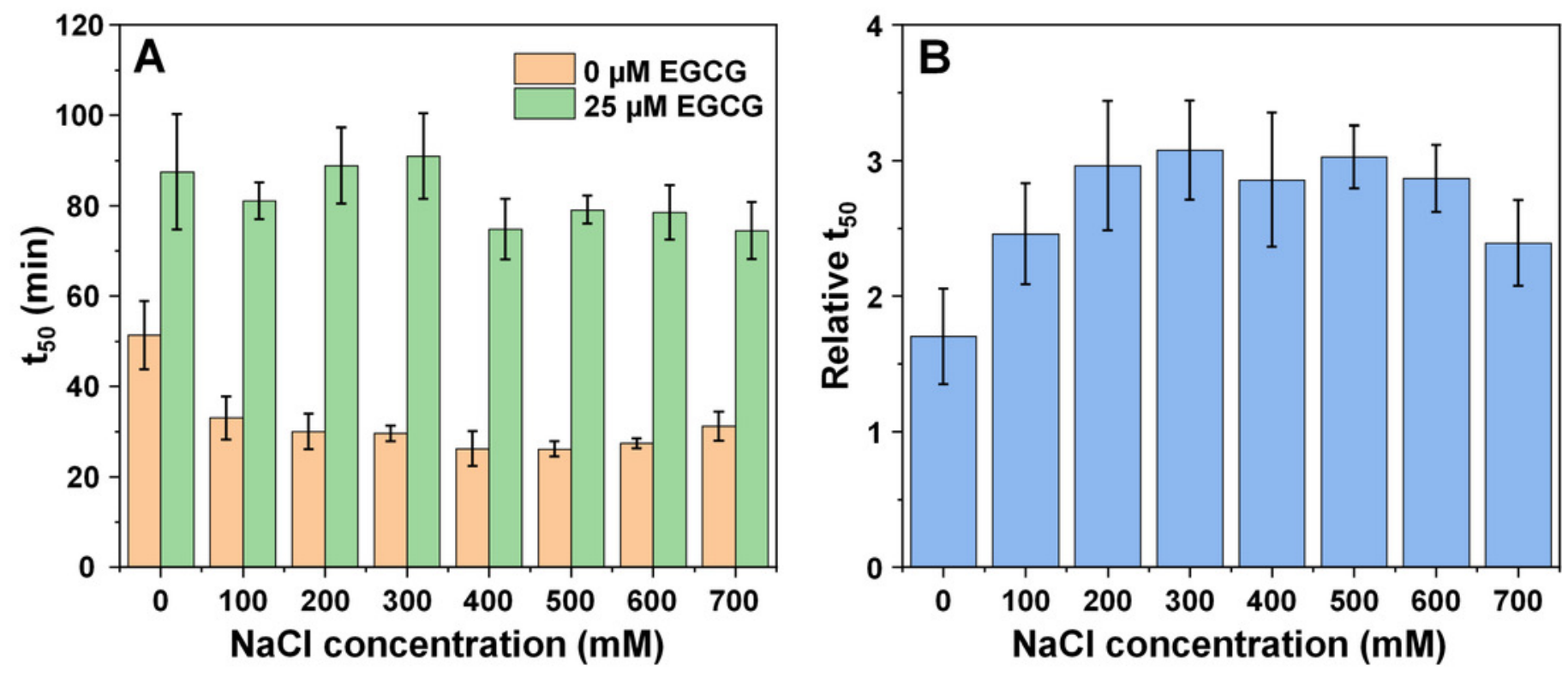